\title{
Effect of Mirror Therapy on the Balance, Gait and Motor Function in Patients with Subacute Stroke
}

\author{
Min-Su Song, Soon-Hee Kang \\ Department of Physical Therapy, Korea National University of Transportation, Chungju, Republic of Korea
}

Purpose: This study examined whether mirror therapy could improve the balance, gait, and motor function of patients with subacute stroke.

Methods: Thirty-three patients with subacute stroke were divided randomly into three groups: experimental group1, experimental group2, and the control group. The patients in experimental group1 performed a mirror therapy program on the unaffected side of the lower extremities, and the patients in experimental group2 performed mirror therapy on the affected side of the lower extremities. Both groups performed the exercise for 30 minutes per session, five times a week for four weeks. The control group did not receive mirror therapy. BBS, POMA, 10MWT, and the BRS were used to evaluate the balance, the quality of gait, gait speed, and the motor function before and after the intervention.

Results: The gait speed increased significantly in the experimental groups1 and 2 after the intervention. The control group showed no significant difference in the gait speed after the intervention. The change in gait speed before and after the intervention showed a significant difference among the groups. Experimental group1 showed a significant increase in the gait speed compared to that of the control group.

Conclusion: This study suggests that mirror therapy could be an effective intervention to improve the gait speed of patients with subacute stroke. On the other hand, there was no difference in the effectiveness of mirror therapy and therapeutic exercise on the balance, gait, and motor function.

Keywords: Mirror therapy, Subacute, Balance, Gait, Motor function

\section{서 론}

뇌졸중은 뇌의 정상적인 혈액 공급에 문제가 발생하여 일어나는 질 환으로 발생 빈도가 높은 신경학적 질환이며, ${ }^{1}$ 사망하지 않아도 이로 인한 후유증이나 합병증으로 환자 본인, 가족, 사회에 큰 영향을 끼친 다. 생활수준의 향상과 의학의 발전에 따라 평균 수명의 증가와 함께 뇌졸중 환자의 수는 점점 증가하고 있다. 뇌졸중의 임상증상은 일반 적으로 운동, 지각 및 언어, 감각, 인지 및 시각 장애 등 여러 합병증을 갖게 된다. 또한, 뇌졸중 발병 후에 자세안정성의 감소, 동적 기립자 세에서의 균형능력 감소 및 기립자세에서의 비대칭적인 체중지지 양 상이 나타난다. 이러한 다양한 신경학적 기능장애를 가진 뇌졸중 환 자는 초기부터 빠른 일상복귀를 위한 앉기, 걷기 등의 체계적인 재활 이 중요하다. ${ }^{5}$ 뇌졸중 환자들의 균형능력이 감소됨에 따라 뇌졸중 환 자들의 보행은 마비측의 체중지지 시간이 짧고 흔듦기가 길기 때문

Received Mar 1, 2021 Revised Apr 26, 2021

Accepted Apr 29, 2021

Corresponding author Soon-Hee Kang

E-mail shkang@ut.ac.kr
에 마비측과 비마비측 간 보폭길이의 차이가 발생하고 보행주기와 속도가 느려지는 특징을 가진다. ${ }^{6}$ 이런 뇌졸중 환자에게 있어서 균형 능력과 보행능력의 회복은 재활치료에서 중요한 목표가 된다. 뇌졸 중 환자의 균형능력, 보행능력 및 신체기능 회복을 위하여 공을 이용 한 방법, 시각적 피드백 훈련, 환측 체중 이동 훈련, 특정 과제 훈련 및 거울치료 등 많은 중재 방법이 적용되어 왔다. 그중 거울치료가 뇌졸 중 환자의 운동기능, 일상생활동작 및 보행속도 등에 긍정적인 효과 가 있음을 보고한 여러 연구들이 있다.8-10

거울치료는 거울을 대상자 몸통 앞의 가운데 놓아 마비측 사지의 시야를 차단하고 비마비측 사지의 움직임을 거울에 투영시켜 양측 사지 모두 정상적인 움직임인 것 같이 시각적 정보를 제공하여 마비 측 사지의 기능을 향상시키는 치료방법이다." ${ }^{1}$ 거울신경 시스템은 동 작관찰과 실행중 나타나는 신경기질의 한 종류로서, 거울신경 시스 템의 영역으로는 1 차 운동겉질(primary motor cortex), 1 차체성감각겉 
질(primary somatosensory cortex) 등이 포함된다. 거울신경 시스템은 시각정보가 운동실행을 위한 겉질 영역을 활성화시킨다는 이론에 기초해 운동수행에 관여하는 겉질 부위가 동작을 관찰함으로써 활 성화될 수 있다. 동작관찰은 보완운동 영역(supplementary motor area) 을 활성화시키며, 이러한 거울신경 시스템을 통해 운동 겉질을 활성 화하는 것을 목표로 다양한 치료가 뇌졸중 재활에 적용되었고, 동작 관찰과 거울신경 시스템은 운동 겉질 활성화와 관련되어 뇌졸중 환 자의 운동 재학습을 촉진시킬 수 있다.12 거울치료를 통한 정상적인 동작을 관찰한 후 그것을 이미지화하고 운동을 실시하는 과정에서 거울 신경세포가 활용되어 운동회복 능력이 촉진되고, 이러한 거울 신경세포는 일반적으로 눈으로 기술을 봄으로써 새로운 기술을 배 우는 것으로 알려져 있다.13

선행연구들에서 거울치료가 상지 및 하지 운동기능 개선에 효과 적인 중재로 보고되고 있으나, 14,15 하지에 적용한 거울치료의 효과는 여전히 불충분하기 때문에 추가적인 무작위 대조시험 연구가 필요하 고, ${ }^{14}$ 특히 아급성기 뇌졸중 환자에게 거울치료를 적용하는 연구가 부족하다. ${ }^{16}$ 또한 현재까지 거울치료의 효과와 거울치료의 운동요소 를 마비측 하지에 적용한 운동치료의 효과를 비교한 연구는 부족하 다. 이에 본 연구는 아급성기 뇌졸중 환자들을 대상으로 비마비측 하 지에 적용한 거울치료와 마비측 하지에 적용한 운동치료가 균형, 보 행 및 운동기능에 어떤 영향을 미치는 지를 알아보고자 실시하였다.

\section{연구 방법}

\section{1. 연구대상}

본 연구의 연구대상자는 C시에 소재한 $\mathrm{C}$ 병원에서 입원치료를 받고 있는 뇌졸중 편마비로 진단받고, 발병 후 1개월 이상 6 개월 이하 경과 한 자, ${ }^{17}$ 수정된 애쉬워스 척도(Modified Ashworth Scale, MAS) 3단계 이하인 자, 한국형 간이-정신상태검사(Mini-Mental State Examination of Korean version, MMSE-K)에서 24점 이상인 자, 브룬스트롬 하지 회
복단계(Brunnstrome Recovery Stage, BRS) 3단계 이상인 자, 보행 보조 기 유무에 상관이 독립적으로 $14 \mathrm{~m}$ 이상을 걸을 수 있는 자 등 선정 기준에 합당한 자들이었다. 연구자는 대상자들에게 연구의 목적과 절차에 관한 설명을 한 다음에 동의서를 받은 후, 총 33 명의 대상자들 을 실험군 $1(\mathrm{n}=11)$ 과 실험군 $2(\mathrm{n}=11)$ 및 대조군 $(\mathrm{n}=11)$ 에 무작위 배 정하였다. 연구대상자의 일반적인 특성은 다음과 같다(Table 1). 본 연 구는 한국교통대학교 생명윤리심의위원회의 승인을 받았다(KNUT IRB 2020-11).

\section{2. 측정방법 및 도구}

1) 균형능력 평가

(1) 한국판 버그균형척도

한국판 버그균형척도(Korea- Berg balance scale, K-BBS)는 일상생활동 작을 응용한 항목으로 앉기, 서기 자세, 자세 변화의 3 대 영역, 총 14 항 목으로 구성되어 있고, 각 항목별 0 점에서 4 점까지 총점은 56 점이다. 검사 결과인 BBS 점수가 높을수록 균형능력이 우수함을 의미한다.

\section{2) 보행능력 평가}

(1) $10 \mathrm{~m}$ 보행검사

$10 \mathrm{~m}$ 보행검사(10 m walk test, 10MWT)는 뇌졸중 환자의 보행 능력을 예측할 수 있는 쉽고 간단한 방법이다. 본 연구에서는 대상자들이 총 $14 \mathrm{~m}$ 를 최고 속도로 걷게 하며 처음 $2 \mathrm{~m}$ 와 마지막 $2 \mathrm{~m}$ 를 측정에서 제 외한 다음에 $10 \mathrm{~m}$ 보행에 걸린 시간을 측정하였다. 대상자가 한번 걷 게 하여 적응하도록 한 후 3 회 측정하였고, 평균시간을 계산한 후 보 행속도로 변환하였다. 모든 대상자들은 3 번 측정 후 평균값을 결과 값으로 사용했다.

\section{(2) 수행중심 이동성 평가}

수행중심 이동성 평가(Performance-Oriented Mobility Assesment, $\mathrm{POMA}$ )는 균형과 보행의 문제를 평가하는 도구 중 하나로써 다양한

Table 1. General characteristics of subjects

\begin{tabular}{|c|c|c|c|c|c|}
\hline & Group $1(n=11)$ & Group $2(n=11)$ & Group $3(n=11)$ & $\chi^{2}$ & $\mathrm{p}$ \\
\hline $\operatorname{Sex}(M / F)$ & $9 / 2$ & $8 / 3$ & $9 / 2$ & 0.363 & 0.834 \\
\hline Affected side (Rt/Lt) & $5 / 6$ & $5 / 6$ & $2 / 9$ & 2.357 & 0.308 \\
\hline Age (yr) & $68.0 \pm 7.6$ & $68.2 \pm 12.7$ & $63.9 \pm 15.5$ & 0.550 & 0.760 \\
\hline Height (cm) & $169.2 \pm 7.2$ & $164.3 \pm 5.1$ & $166.5 \pm 7.5$ & 4.916 & 0.086 \\
\hline Weight (kg) & $68.9 \pm 6.7$ & $63.1 \pm 11.5$ & $59.1 \pm 9.6$ & 6.324 & $0.042^{*}$ \\
\hline BRS (stage) & $4.55 \pm 1.04$ & $4.73 \pm 1.10$ & $5.45 \pm 0.52$ & 5.112 & 0.078 \\
\hline MAS (score) & $0.2 \pm 0.4$ & $0.2 \pm 0.4$ & $0.0 \pm 0.0$ & 2.207 & 0.332 \\
\hline Onset (month) & $1.7 \pm 1.2$ & $2.1 \pm 1.5$ & $1.7 \pm 1.4$ & 0.667 & 0.717 \\
\hline
\end{tabular}

Mean \pm SD, Group 1: Mirror Therapy training group, Group 2: Affected side movement training group, Group 3: control group.

BRS: Brunnstrome recovery stage, MAS: Modified Ashworth Scale, Rt: Right, Lt: Left. 
뇌졸중 및 파킨슨, 치매 등의 환자를 대상으로 움직임 손상을 측정하 기 위하여 사용되며 치료효과를 평가하기 위해서도 사용된다. 이 평 가도구는 균형척도와 보행척도로 구성되어 있으며, 본 연구에서는 보행척도만을 사용하여 대상자들의 보행을 평가하였다. 보행척도는 보행시작, 보폭과 높이, 보폭의 대칭성, 보행의 연속성, 경로, 체간, 보 행 시 발의 위치를 평가한다. 각각의 항목은 수행 내용에 따라 0 점에 서 2점까지 점수를 주며, 보행 척도는 12점이다.

\section{3) 운동기능 평가}

(1) 브룬스트롬 운동 회복 단계

브룬스트롬 운동 회복 단계(BRS)는 뇌졸중 후 편마비 환자의 움직임 조절을 통한 회복과정을 질적으로 평가한 항목으로 상지와 손 그리 고 하지의 운동회복 과정을 6단계로 구분하며, 점수가 높을수록 회 복 정도가 높은 것을 의미한다. 본 연구에서는 하지의 운동회복 과정 6 단계를 이용하여 평가하였다. 1 단계는 능동적인 근수축이 전혀 관 찰되지 않고 깊은힘줄반사 등의 반사활동과 경직 등의 소견이 관찰 되지 않는 단계이다. 2 단계는 깊은힘줄반사 등의 반사활동이 관찰되 기 시작하면서 근수축이 가능하기는 하나 능동적 관절운동은 관찰 되지 않고, 경미한 경직의 소견이 관찰되는 단계이다. 3 단계는 깊은힘 줄반사의 항진과 심한 경직이 관찰되면서 하지의 근수축 시 엉덩관 절 굽힘, 무릎관절 굽힘, 발목관절 발등굽힘이 동시에 일어나는 단계 이다. 4 단계는 앉은 자세에서 무릎관절이 $90^{\circ}$ 이상이 가능하고 발뒤 꿈치를 땅에 댄 상태에서 발목관절의 발등굽힘이 가능한 상태이다 (하지의 각 관절에서 독립적인 운동이 가능해지기 시작하는 단계). 5 단계는 깊은힘줄반사와 경직이 감소하기 시작하면서 하지 각 관절의 독립적인 운동이 더욱 현저해지는 단계이다(엉덩관절을 폄 시킨 기 립 자세에서 무릎관절을 굽힘 시킬 수 있고, 무릎관절을 폄 시킨 상 태에서 발목관절의 발등굽힘이 가능해지는 단계). 6 단계는 깊은힘줄 반사가 정상화되고 경직의 소견이 미미 해지며 하지 각 관절의 독립 운동이 거의 자유로워진 상태이다(기립자세에서 엉덩관절의 바깥돌 림이 가능하고 앉은 자세에서 무릎관절의 회전과 발목관절의 안쪽 번짐 및 바깥 번짐이 가능해지는 단계).

\section{3. 실험 절차}

본 연구에 동의하고 대상자의 선정기준에 합당한 총 33 명의 아급성 기 뇌졸중 환자들을 선정한 후, $\mathrm{BBS}, \mathrm{POMA}, 10 \mathrm{MWT}, \mathrm{BRS}$ 등 측정도 구들을 사용하여 균형, 보행 및 운동기능을 평가하였다. 그런 다음에 대상자들을 실험군 1 , 실험군 2 및 대조군의 세 집단에 각 11 명씩 무 작위 배정한 다음에, 4 주간 동안 각 집단별, 거울치료(비마비측 하지 사용)와 일반적인 물리치료, 거울치료에서 사용된 운동치료(마비측 하지 사용)와 일반적인 물리치료 및 일반적인 물리치료를 적용하였
고, 중재 후 동일한 측정도구들을 사용하여 대상자들의 균형, 보행 및 운동기능을 평가하였다.

\section{4. 중재 방법}

실험군 1 의 대상자들은 거울치료를 4 주간, 주당 5 회, 회기당 30 분 동 안수행하였다. 실험군 1 의 대상자들이 거울치료를 하는 동안, 대상자 의 두 다리 사이에 거울을 배치하여 마비측 사지를 보지 못하도록 거 울을 설치하고, 반사 표면이 비마비측 다리를 계속 향하도록 한 다음 에, 비마비측 하지로 브룬스트롬 하지 회복단계(BRS)의 3-6단계의 운 동요소들을 사용하여 수행하였고, 1 주차에는 BRS 3 단계의 운동, 2 주 차에서는 BRS 4단계의 운동, 3 주차에서는 BRS 5 단계의 운동, 4 주차 에서는 BRS 6단계의 운동 등으로 점차적으로 운동의 난이도를 높여 서 실시하였다. 매주마다 각 운동을 치료사가 대상자들에게 알려주 고 환자가 2-3회 반복하게 한 다음에는 더 이상 구두지시를 하지 않 고 치료사 감독 하에 대상자들이 운동을 수행하였고, 거울치료를 하 는 동안 세트 사이 휴식시간을 2 분간 제공하여 피로로 인한 영향을 감소시켰다. 대상자들이 각 단계의 운동수행이 불가능한 경우에는 보조 테이블을 사용하도록 허용하여 보조수준을 높였다. 거울치료 의 주차별 운동방법은 다음과 같다(Table 2).

실험군 2 의 대상자들은 거울없이 마비측 하지로 실험군1에서 수행 한 동일한 하지 운동을 4 주간, 주당 5 회, 회기당 30 분 동안 수행한 반 면에, 대조군은 특별한 치료를 하지 않았다.

추가적으로 실험군 1 과 실험군 2 및 대조군의 모든 대상자들은 중 추신경계발달치료(Neuro Development Treatment, NDT)에 근거한 운 동치료 30 분 및 보행훈련 30 분, 기능적 전기자극 치료(Functional Electrical Stimulation, FES) 30 분 등을 포함한 일반적인 물리치료를 총 1 시 간 30 분 동안 주당 5 회, 4 주간 받았다.

\section{5. 자료 분석}

본 연구에서 수집된 자료를 분석하기 위해 SPSS Win. 21.0 Package를 사용하였다. Shapiro-Wilk 검정을 이용하여 정규성 검정을 실시한 결 과 정규성이 성립되지 않아 비모수 통계를 사용하였다. 대상자의 일 반적인 특성 및 사전종속변수의 동질성 검정을 위해 카이제곱 검정 (Chi squared test) 및 Kruskal Wallis H 검정을 시행하였다. 각 군의 훈련 전후 군내 종속변수의 변화를 알아보기 위해 Wilcoxon 부호-순위 검 정을 이용하여 분석하였다. 또한 훈련 전후 군 간 종속변수의 변화량 을 비교하기 위하여 Kruskal Wallis H 검정을 이용하였고 사후 검정을 위하여 Mann-Whitney U 검정을 이용하여 분석하였다. 모든 통계학 적 유의수준은 $\alpha=0.05$ 로 설정하였다. 
Table 2. Mirror therapy program

\begin{tabular}{|c|c|c|c|}
\hline Week & Composition of exercise & Exercise Prescription & Picture of exercise \\
\hline 1 & $\begin{array}{l}\text { Combined hip flexion, knee flexion, and ankle dorsiflexion in the sitting } \\
\text { position. } 20 \text { times }\end{array}$ & $\begin{array}{l}-20 \text { times per set, } 5 \text { sets. } \\
-2 \text { minutes rest between sets }\end{array}$ & \\
\hline 2 & $\begin{array}{l}\text { Knee flexion exceeding } 90^{\circ} \text { and ankle dorsiflexion with the heel on the } \\
\text { floor in the sitting position. } 20 \text { times }\end{array}$ & $\begin{array}{l}-20 \text { times per set, } 5 \text { sets. } \\
-2 \text { minutes rest between sets }\end{array}$ & \\
\hline 3 & $\begin{array}{l}\text { Isolated knee flexion with the hip extended in the standing position. } \\
10 \text { times } \\
\text { Isolated ankle dorsiflexion with the knee extended in the standing } \\
\text { position. } 10 \text { times }\end{array}$ & $\begin{array}{l}-20 \text { times per set, } 5 \text { sets. } \\
-2 \text { minutes rest between sets }\end{array}$ & \\
\hline 4 & $\begin{array}{l}\text { Hip abduction in the standing position. } 10 \text { times } \\
\text { Knee rotation with inversion of the ankle in the sitting position. } 5 \text { times } \\
\text { Knee rotation with eversion of the ankle in the sitting position. } 5 \text { times }\end{array}$ & $\begin{array}{l}-20 \text { times per set, } 5 \text { sets. } \\
-2 \text { minutes rest between sets }\end{array}$ & \\
\hline
\end{tabular}

결 과

\section{1. 대상자의 일반적 특성}

실험군 1 , 실험군 2 및 대조군의 대상자들의 성별, 우측마비 및 좌측 마비 비율, 나이, 키, 체중, 브룬스트롬 회복 단계, 근 긴장도 및 유병기
간에서 집단 간 유의한 차이가 없었으나 체중은 집단 간 유의한 차이 가 있었다(p<0.05). 성별, 우측마비 및 좌측마비 비율, 나이, 키, 브룬 스트롬 회복 단계, 근 긴장도 및 유병기간에서 집단 간 동질성이 확인 되었다. 연구대상자들의 특성과 동질성 검정 결과는 다음과 같다(Table 1). 


\section{2. 종속변수의 동질성 검정}

실험군 1 , 실험군 2 및 대조군의 BBS, POMA, $10 \mathrm{MWT}, \mathrm{BRS}$ 등 종속변 수에 대한 동질성 검정을 한 결과, 모든 종속변수에서 집단 간 유의한 차이가 없었으므로 동질성이 확인되었다(Table 3).

\section{3. 균형능력의 변화}

실험군 1 , 실험군 2 및 대조군의 세 집단 모두 훈련 전보다 훈련 후에 $\mathrm{BBS}$ 점수가 유의하게 증가하였으나 $(\mathrm{p}<0.05)$, 집단 간 $\mathrm{BBS}$ 점수의 변화 량에 유의한차이는 없었다( $\mathrm{p}>0.05)($ Table 3$)$.

\section{4. 보행능력의 변화}

\section{1) 수행중심 이동성 평가 점수의 변화}

실험군 1 , 실험군 2 및 대조군의 세 집단 모두 훈련 전보다 훈련 후에 $\mathrm{POMA}$ 점수가 유의하게 증가하였으나 $(\mathrm{p}<0.05)$, 집단 간 POMA 점수 의 변화량에 유의한 차이는 없었다( $\mathrm{p}>0.05)($ Table 3$)$.

\section{2) 보행속도의 변화}

실험군 1 과 실험군 2 는 훈련 전보다 훈련 후에 보행속도가 유의하게
증가하였으나 $(\mathrm{p}<0.05)$, 대조군은 유의한 증가가 없었다 $(\mathrm{p}>0.05)$. 집단 간 훈련 전후 보행속도의 변화량은 유의한 차이가 있었으며 $(\mathrm{p}<0.05)$, 실험군 1 이 대조군보다 보행속도의 변화량이 유의하게 더 큰 것으로 나타났다 $(\mathrm{p}<0.05)($ Table 3$)$.

\section{5. 운동기능의 변화}

실험군 1 , 실험군 2 및 대조군의 세 집단 모두 훈련 전보다 훈련 후에 $\mathrm{BRS}$ 점수가 유의하게 증가하였으나 $(\mathrm{p}<0.05)$, 집단 간 BRS 점수의 변 화량에 유의한차이는 없었다( $\mathrm{p}>0.05)($ Table 3$)$.

\section{고 찰}

본 연구의 목적은 아급성기 뇌졸중 환자들을 대상으로 거울치료가 균형, 보행 및 운동기능에 어떤 영향을 미치는지를 알아보기 위한 것 이었다. 그 결과 모든 군에서 균형능력, 보행의 질 및 운동기능이 훈련 전보다 훈련 후에 유의하게 향상되었고, 보행속도는 거울치료를 받은 실험군1이 대조군보다 유의하게 더 증가하였다.

본 연구결과에서 세 집단 모두 BBS점수가 훈련 전보다 훈련 후에

Table 3. Changes in balace, gait and motor function after intervention within group and between groups

\begin{tabular}{|c|c|c|c|c|c|}
\hline Group Variable & Group $1(n=11)$ & Group2 $(n=11)$ & Group3 $(n=11)$ & $\chi^{2}$ & $p$ \\
\hline \multicolumn{6}{|l|}{ BBS (score) } \\
\hline Pre & $41.64 \pm 11.38$ & $39.82 \pm 9.54$ & $48.73 \pm 5.24$ & 4.138 & 0.126 \\
\hline Post & $48.82 \pm 7.52$ & $46.00 \pm 6.69$ & $53.09 \pm 2.26$ & & \\
\hline Post-Pre & $7.18 \pm 8.41$ & $6.18 \pm 3.82$ & $4.36 \pm 5.71$ & 3.435 & 0.180 \\
\hline z & -2.938 & -2.943 & -2.938 & & \\
\hline $\mathrm{p}$ & $0.003^{*}$ & $0.003^{*}$ & $0.003^{*}$ & & \\
\hline \multicolumn{6}{|l|}{ POMA (score) } \\
\hline Pre & $8.45 \pm 2.81$ & $8.64 \pm 2.25$ & $10.09 \pm 0.83$ & 2.915 & 0.233 \\
\hline Post & $10.55 \pm 1.51$ & $9.82 \pm 1.72$ & $11.27 \pm 0.90$ & & \\
\hline Post-Pre & $2.09 \pm 2.26$ & $1.18 \pm 0.98$ & $1.18 \pm 1.08$ & 0.537 & 0.764 \\
\hline z & -2.714 & -2.565 & -2.414 & & \\
\hline $\mathrm{p}$ & $0.007^{*}$ & $0.010^{*}$ & $0.016^{*}$ & & \\
\hline \multicolumn{6}{|l|}{$10 \mathrm{MWT}(\mathrm{m} / \mathrm{s})$} \\
\hline Pre & $0.63 \pm 0.31$ & $0.59 \pm 0.27$ & $0.73 \pm 0.12$ & 0.978 & 0.613 \\
\hline Post & $0.85 \pm 0.31$ & $0.69 \pm 0.19$ & $0.79 \pm 0.13$ & & \\
\hline Post-Pre & $0.22 \pm 0.23$ & $0.10 \pm 0.11$ & $0.05 \pm 0.09$ & 7.667 & $0.022^{*}$ \\
\hline z & -2.934 & -2.756 & -1.60 & & \\
\hline $\mathrm{p}$ & $0.003^{*}$ & $0.006^{*}$ & 0.11 & & \\
\hline \multicolumn{6}{|l|}{ BRS } \\
\hline Pre & $4.55 \pm 1.04$ & $4.73 \pm 1.10$ & $5.45 \pm 0.52$ & 5.112 & 0.078 \\
\hline Post & $5.55 \pm 0.82$ & $5.45 \pm 0.93$ & $6.00 \pm 0.00$ & & \\
\hline Post-Pre & $1.00 \pm 1.00$ & $0.73 \pm 0.65$ & $0.55 \pm 0.52$ & 1.195 & 0.550 \\
\hline z & -2.414 & -2.53 & -2.449 & & \\
\hline $\mathrm{p}$ & $0.016 *$ & $0.011 *$ & $0.014 *$ & & \\
\hline
\end{tabular}

Mean \pm SD, Group 1: mirror therapy training group, Group 2: affected side movement training group, Group 3: control group. BBS: Berg Balance scale, POMA: Performance Oriented Mobility Assessment, 10MWT: 10 meter walk test, BRS: Brunnstrome recovery stage. 
유의하게 증가하였으나 $\mathrm{BBS}$ 점수의 훈련 전후 변화량은 집단 간 차이 가 없었다. 이런 연구결과와 유사하게 20 명의 만성기 환자를 두 집단 으로 나누어 Wii fit과 거울을 이용하여 균형훈련을 실시한 선행연구 에서 무릎관절의 고유수용성 감각, 정적균형 및 동적균형이 훈련 전 보다 훈련 후에 유의하게 개선되었으나 집단 간 비교에서는 고유수 용성 감각을 제외한 나머지 모든 변수에서 유의한 차이가 나타나지 않았다. ${ }^{18}$ 또한 본 연구결과와는 다르게 또 다른 선행연구에서는 13 명 의 뇌졸중 환자를 대상으로 거울치료를 6 주간, 주 5 회, 30 분간 실시 한 결과 BBS, TUG, 족저압, 자세동요 및 전체 압력분포(total pressure) 가 훈련 전보다 후에 집단 내, 집단 간에서 향상되었다고 보고하였 다. ${ }^{19}$ 이와 같은 연구 결과의 차이는 두 연구에서 적용된 훈련기간 또 는 대상자들의 유병기간에 따른 차이로 다른 결과가 나타났을 것이 다. $\mathrm{POMA}$ 의 보행척도 점수의 집단 내 비교에서 세 집단 모두 유의하 게 향상되는 결과가 나타났지만, 집단 간 차이는 나타나지 않았다. 그 이유는 대상자들이 아급성기 환자일지라도 독립적으로 보행이 가능 한 정도의 높은 기능적 수준을 가지고 있었고, 모든 집단에서 일반적 인 물리치료를 받았으므로 기능적 수준이 낮은 환자들에 비하여 중 재효과가 덜 나타났을 것으로 사료된다. 이를 뒷받침하는 근거로 급 성기 이후 뇌졸중 환자의 재활치료 효과는 중등도 이상의 의존성을 보이는 환자에게서 더 잘 나타난다고 보고된 선행연구가 있다.20.21

$10 \mathrm{MWT}$ 를 사용해 측정한 보행속도에서 실험군 1과 실험군 2 가 유 의하게 보행속도가 증가하였으며, 실험군1이 대조군보다 유의하게 보 행 속도가 증가하였다. 이러한 결과와 일치하게 거울을 이용하여 뒤 로 걷기 운동을 수행한 선행연구에서 훈련 전보다 훈련 후에 거울을 이용한 실험군이 대조군에 비해 보행속도가 향상되었다고 보고하였 다.2 본 연구에서 실험군 1 이 대조군보다 유의하게 보행속도가 증가 한 이유는 실험군 1 의 대상자들이 거울치료를 통한 정상적인 동작을 본 후 그것을 이미지화하고 운동을 수행하는 과정에서 뇌의 정상측 반구가 거울 신경세포 및 마비측 사지에 상응하는 운동경로에 흥분 성을 증가시킴으로써 운동기능의 회복을 촉진시켰을 것으로 생각된 다. ${ }^{23}$ 또한 시각적 피드백을 통해 자세조절 능력이 향상됨으로써 보행 속도가 증가한 것으로 생각된다.22 이러한 연구결과와 다르게 Kim 등 24 은 34 명의 뇌졸중 환자를 실험군과 대조군으로 나누어 4 주간 거울치 료 및 거짓치료를 적용한 결과, 실험군과 대조군 모두 보행속도가 집 단 내에서 증가하였으나 집단 간에는 유의한 차이가 나타나지 않았 다. 이러한 결과가 본 연구결과와 다르게 나타난 것은 실험군1이 거울 치료와 함께 일반적인 물리치료를 병행하여 중재를 하였으나 선행연 구에서는 실험군이 시각적 피드백을 이용한 집중적인 균형치료만을 적용하는 등 중재 방법과 중재시간이 달랐기 때문인 것으로 사료된 다.

본 연구에서 훈련 전보다 훈련 후에 BRS단계가 집단 내에서 향상
되었으나, 집단 간에서는 차이가 없었다. 본 연구결과와 유사하게 뇌 졸중환자 65 명을 대상으로 8 주간 거울치료를 실시한 선행연구 결과 에서 BRS단계가 향상되었으나 집단 간 차이는 없었다고 보고하였 다. ${ }^{25}$ 본 연구결과와 다르게 아급성기 뇌졸중 환자를 대상으로 4 주간 거울치료를 수행한 선행연구에서는 BRS단계가 훈련 전보다 훈련 후 에 향상되었으며, 거울치료를 실시한 실험군이 대조군보다 더 유의하 게 향상되었다고 보고하였다. ${ }^{14}$ 이와 같이 연구결과에 차이가 있었던 것은 대상자들의 BRS단계가 선행연구의 대상자들보다 더 높은 단계 로 더 높은 운동기능을 가졌기 때문이라고 생각된다.

결론적으로 아급성기 뇌졸중 환자들의 보행속도를 향상시키기 위 하여 거울치료와 일반적인 물리치료를 병행하는 중재가 일반적인 물 리치료만을 적용하는 것 보다 더 효과적이라고 볼 수 있다. 그러나 균 형, 보행 및 운동기능에 대한 거울치료와 마비측 하지로 수행되는 운 동치료의 효과에 차이가 없는 것으로 사료된다.

본 연구의 제한점으로는 연구대상자의 수가 적었고, 기능적으로 높은 수준의 뇌졸중 환자를 대상으로 수행한 연구였기 때문에 연구 결과를 모든 아급성기 뇌졸중 환자들에게 일반화시키기에는 제한점 이 있다. 따라서 향후 연구에서는 더 많은 수의 대상자와 낮은 기능 수준을 포함한 아급성기 뇌졸중 환자를 대상으로 연구가 이루어져 야할 필요가 있는 것으로 사료된다.

\section{REFERENCES}

1. Bae SS, Lee JH. The study of clinical pictures and received rehabilitation service patterns of stroke patients. J Kor Phys Ther. 2001;13(3):799-814.

2. Kim KT, An JD, Kim BY et al. Current epidemiologic status of stroke. J Korean Acad Rehabil Med. 2003;27(2):178-85.

3. Mercier L, Audet T, Hébert R et al. Impact of motor, cognitive, and perceptual disorders on ability to perform activities of daily living after stroke. Stroke. 2001;32(11):2602-8.

4. De Oliveira CB, de Medeiros ÍRT, Ferreira NA et al. Balance control in hemiparetic stroke patients: Main tools for evaluation. J Rehabil Res Dev. 2008;45(8):1215-26.

5. Kil SR, Son SM. Effects of the motivation for rehabilitation on the functional performance of stroke patients. J Kor Phys Ther. 2020;32(1):3943.

6. Wagenaar RC, Beek W. Hemiplegic gait: a kinematic analysis using walking speed as a basis. J Biomech. 1992;25(9):1007-15.

7. Baek KH, Lim HW. Effect of spiral elastic band on gait function in patients with chronic stroke. J Kor Phys Ther. 2019;31(4):169-75.

8. Salem HMA, Huang X. The effects of mirror therapy on clinical improvement in hemiplegic lower extremity rehabilitation in subjects with chronic stroke. Int J Biolo Biomed Eng. 2015;9(2):163-6.

9. Wang $\mathrm{H}$, Zhao Z, Jiang P et al. Effect and mechanism of mirror therapy on rehabilitation of lower limb motor function in patients with stroke hemiplegia. Biomed Res. 2017;28(22):10165-70.

10. Arya KN, Pandian S, Kumar V. Effect of activity-based mirror therapy 
on lower limb motor-recovery and gait in stroke: a randomised controlled trial. Neuropsychol Rehabil. 2019;29(8):1193-210.

11. Deconinck FJ, Smorenburg AR, Benham A et al. Reflections on mirror therapy: a systematic review of the effect of mirror visual feedback on the brain. Neurorehabil Neural Repair. 2015;29(4):349-61.

12. Zhang JJ, Fong KN, Welage $\mathrm{N}$ et al. The activation of the mirror neuron system during action observation and action execution with mirror visual feedback in stroke: a systematic review. Neural Plast. 2018;2018: 2321045.

13. Sütbeyaz S, Yavuzer G, Sezer N et al. Mirror therapy enhances lower-extremity motor recovery and motor functioning after stroke: a randomized controlled trial. Arch Phys Med Rehabil. 2007;88(5):555-9.

14. Broderick P, Horgan F, Blake C et al. Mirror therapy for improving lower limb motor function and mobility after stroke: a systematic review and meta-analysis. Gait \& posture. 2018;63:208-20.

15. Zeng W, Guo Y, Wu G et al. Mirror therapy for motor function of the upper extremity in patients with stroke: a meta-analysis. J Rehabil Med. 2018;50(1):8-15.

16. Scordalakes H. A meta-analysis evaluating the effectiveness of mirror therapy vs modified constraint-induced movement therapy on upper extremity hemiparesis and quality of life in patients with subacute stroke. California State University. Dissertation of Doctorate Degree. 2020.

17. Moon S, Keum D. Effect of east-west integrative rehabilitation on activities of daily living and cognitive functional recovery in stroke patients: a retrospective study. J Korean Med Rehabil. 2020;30(2):105-23.

18. Sim GS, Jeon HS. Comparison of the effects of wii balance games and mirror self-balancing exercises on knee joint proprioception and balance in chronic stroke patients. Phys Ther orea. 2017;24(1):30-40.

19. Ji SG, Nam GW, Kim MK et al. The effect of visual feedback training using a mirror on the balance in hemiplegic patients. J Korean Soc Phys Med. 2011;6(2):153-63.

20. Briggs DE, Felberg RA, Malkoff MD et al. Should mild or moderate stroke patients be admitted to an intensive care unit? Stroke. 2001;32(4): 871-6.

21. Kwon YW, Lee J, Jeon J et al. Comparison of functional recovery status according to rehabilitation therapy in stroke patients. J Korean Acad Rehabil Med. 2002;26(4):370-3.

22. Kang TW, Kim BR. The effect of backward walking exercise using a mirror on balance and gait in patients with stroke. Korean Soc Phys Med. 2018;13(2):53-60.

23. Yavuzer G, Selles R, Sezer N et al. Mirror therapy improves hand function in subacute stroke: a randomized controlled trial. Arch Phys Med Rehabil. 2008;89(3):393-8.

24. Kim MK, Ji SG, Cha HG. The effect of mirror therapy on balance ability of subacute stroke patients. Hong Kong Physiother J. 2016;34:27-32.

25. Baek NY. Effects of mirror therapy on hemiplegia in the function of lower extremity. Daegu University. Dissertation of Master's Degree. 2009. 